\title{
Characteristics of Magnetic Field Assisting Plasma GMAW-P
}

\author{
The effect of the magnetic field intensity on droplet transition in \\ plasma-GMAW-P hybrid welding was studied
}

BY J. YU, B. WANG, H. ZHANG, Q. WANG, L. WEI, P. CHEN, P. HE, AND J. FENG

\begin{abstract}
The droplet transfer and voltage-current characteristics of gas metal arc welding (GMAW) in single-pulsed GMAW (single GMAW-P), plasma pulsed GMAW (plasma GMAW-P), and plasma-GMAW-P with a magnetic field were studied using the synchronous acquisition system of high-speed camera and electric signals. The results showed the plasma arc and magnetic field had a significant effect on the droplet transfer process. The indirect arc of the plasma and gas metal arc emerged in the pulse peak phase causing a shunt phenomenon of the GMAW current. The period of the indirect arc was increased under the action of the magnetic field. In hybrid plasma GMAW-P, when the GMAW current did not exceed 140 A, several pulsed one-drop free transfers occurred and the droplet transfer period decreased with the increase in the plasma welding current; when the GMAW current exceeded $140 \mathrm{~A}$, and the plasma welding current was less than 180 A, spray transfer was formed. The droplet transfer transformed into a projected transfer when the plasma welding current increased to 180 A. In plasma-GMAW-P hybrid welding with a magnetic field, the magnetic field had a slight effect on the transfer period When the GMAW current did not exceed $140 \mathrm{~A}$, the droplet transfer was mainly repelled transfer. The detaching location was on the right side of the wire when the magnetic field current was less than $3 \mathrm{~A}$. When the magnetic field current exceeded $3 \mathrm{~A}$, it was below or on the left side of the wire. When the GMAW current exceeded 140 $A$ and the magnetic field current was less than 5 A, spray transfer was formed, but the droplet transfer mode transformed into a projected transfer with a magnetic field current of $5 \mathrm{~A}$.
\end{abstract}

\section{KEYWORDS}

- Droplet Transfer • Voltage-Current Characteristics

- Magnetic Field • Shunt Phenomenon

- Detaching Location

\section{Introduction}

Hybrid welding technology has been regarded as one of the effective methods to improve quality and efficiency in recent years (Refs. 1-4). Hybrid welding technology is mainly composed of two or more heat sources, including laser-arc hybrid welding and double-arc hybrid welding (Ref. 5). Laser-arc hybrid welding has been applied successfully because of its good ability to bridge root openings and deep penetration, but there are shortcomings such as the difficulty to weld materials with high reflectivity, the porosity problem of the thick plate, and higher equipment costs (Ref. 6). Compared with laser-arc hybrid welding, double-arc hybrid welding has the advantages of low cost, easy operation, better welding accessibility, and higher deposition rate. Therefore, the welding method will have wide-ranging applications (Refs. 7, 8). The plasma-gas metal arc welding (plasma GMAW) hybrid process, proposed by Essers and Liefkens in Philips Research Laboratories, uses two different heat sources of the plasma and gas metal arcs to form one molten pool and thus enhances welding efficiency, which is superior to a single heat source (Refs. 9, 10).

At present, plasma-GMA hybrid welding is divided into two categories: coaxial hybrid welding and paraxial hybrid welding. For example, Bai et al. demonstrated the spray and projected transfer were proved to be the most optimal metal transfer modes through comparing the electronic signal, droplet transition, weld appearance, and penetration in the plasma-GMAW hybrid process. The orthogonal experiment proved the order of the influence factors of the plasmaGMAW hybrid parameters on aluminum weld porosity were as follows: plasma gas flow rate, GMAW voltage, welding speed, wire feed rate, and plasma current (Refs. 11, 12).

Cai et al. showed the corrosion resistance of the welded joint by the plasma-GMAW hybrid method with optimized parameters was higher than that of the base metal in a $0.5 \mathrm{M}-\mathrm{NaCl}$ solution at room temperature (Ref. 13).

Lee et al. testified there were three types of smut phenomenon in plasma-GMA hybrid welding. The plasma current directly affected the type of smut phenomenon by changing metal transfer modes. With the increase in the plasma current, smut phenomenon was changed as follows: smut outside the welding bead $\rightarrow$ smut spots on the welding bead $\rightarrow$ smut inside the welding bead (Refs. 14, 15).

The majority of the research focused on coaxial hybrid 


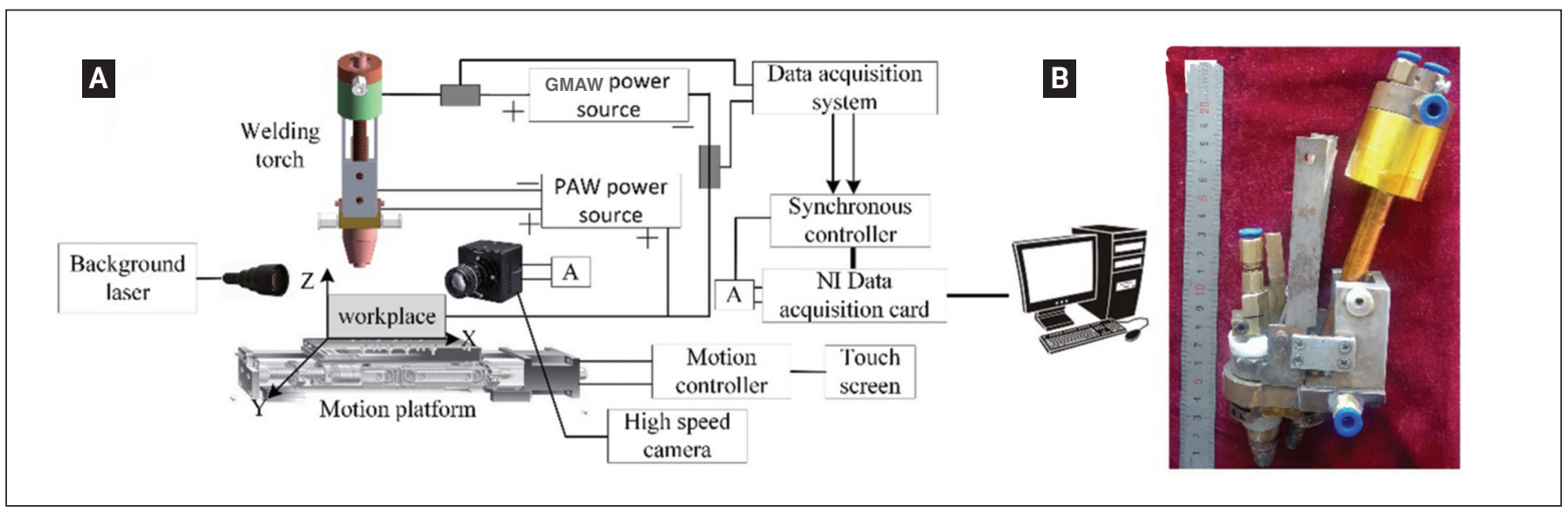

Fig. 1 - Experimental setup: A - Schematic diagram of the plasma-GMAW-P with a magnetic field hybrid process; $B-a$ picture of the hybrid welding torch.

Table 1- Chemical Composition of the Base and Filler Metals

\begin{tabular}{cccccc} 
Element (wt-\%) & C & Mn & Si & S & P \\
\hline Q235B & $0.12 \sim 0.20$ & $0.12 \sim 0.20$ & $\leq 0.40$ & $\leq 0.40$ & $\leq 0.045$ \\
ER50-6 & $0.05 \sim 0.15$ & $1.40 \sim 1.85$ & $0.80 \sim 1.15$ & $0.80 \sim 1.15$ & 0.025 \\
\hline
\end{tabular}

welding rather than paraxial hybrid welding. A tandem, both plasma and gas metal arc, was realized in the single paraxial torch, and the wire could be preheated by the plasma arc in the paraxial plasma-GMAW hybrid process. Yurtisik et al. showed duplex stainless steel could be welded successfully by super-GMAW, which improved welding efficiency and joint performance compared with a single welding method (Ref. 16).

In addition, pulsed GMAW (GMAW-P) maintained the arc in the pulse base stage and melted wire in the pulse peak stage, thus achieving the controlled metal transfer process (Refs. 17-19). Compared with conventional GMAW, GMAW$P$ could be widely used in manufacturing because of better deposition efficiency and weld quality (Refs. 20-22).

Hence, the plasma-GMAW-P hybrid system was established with the assistance of the external magnetic field. Meanwhile, a hybrid welding torch was also designed and manufactured, which not only realized the organic combination of the plasma arc and gas metal arc with reserving their respective characteristics, but also achieved the space optimization of the plasma and gas metal arcs. In addition, the effect of the plasma arc and magnetic field on the droplet transfer of GMAW-P was studied by capturing high-speed images and electric signals.

\section{Experimental System}

Q235B low-carbon steel was chosen as the base metal, and ER50-6 wire with a $1.2 \mathrm{~mm}$ diameter was selected as the filler metal. The chemical compositions of base metal and welding wire are shown in Table 1 . The dimensions of the specimens were $200 \times 100 \times 8 \mathrm{~mm}$. The specimens were polished with a steel brush to remove the oxide film, then cleaned with alcohol and acetone to remove the oily soil before welding.

A schematic diagram of the plasma-GMAW-P system with a magnetic field hybrid process and actual picture of the hybrid welding torch are shown in Fig. 1, with the former consisting of a hybrid welding torch, excitation equipment, welding power source, high-speed imaging camera system with a $4000 \mathrm{frame} / \mathrm{s}$ owing filter system, background laser beam, current and voltage sensors, data acquisition, and control system. The hybrid welding torch was composed of a plasma torch, and a GMAW torch at a certain angle with the axis of a plasma torch, which was fixed on the welding robot. In the present welding system, the plasma arc was established by using the direct current pulse plasma power source under the direct current electrode positive (DCEP) condition (maximum current of $300 \mathrm{~A}$ ). The gas metal arc was performed under the direct current electrode negative (DCEN) condition (maximum current of $400 \mathrm{~A}$ ). The magnetic field was realized by the direct current power source (maximum current of $30 \mathrm{~A}$ ). The high-speed imaging camera system was composed of a FASTCAM Mini UX 50 camera and AF Micro NIKKOR (105 mm, 1:2.8 D) lens with 808-nm filter. The diameter of the tungsten electrode was $3.2 \mathrm{~mm}$ in all experiments. The high-speed camera and background laser beam were fixed on both sides of the motion platform, perpendicular to the welding direction, to observe the image of the droplet transfer.

\section{Experimental Procedure}

In all experiments, plasma current, welding speed, nozzle height, plasma shielding gas flow rate, shielding gas flow rate, GMAW-P current, and magnetic current were recorded in de- 

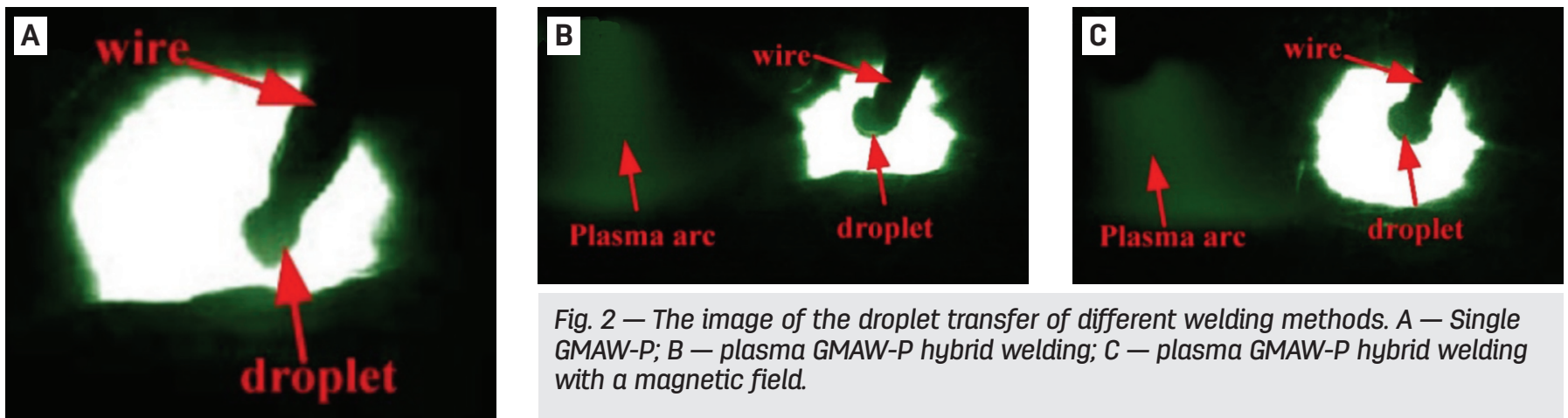

Fig. 2 - The image of the droplet transfer of different welding methods. A - Single GMAW-P; B - plasma GMAW-P hybrid welding; $C$ - plasma GMAW-P hybrid welding with a magnetic field.

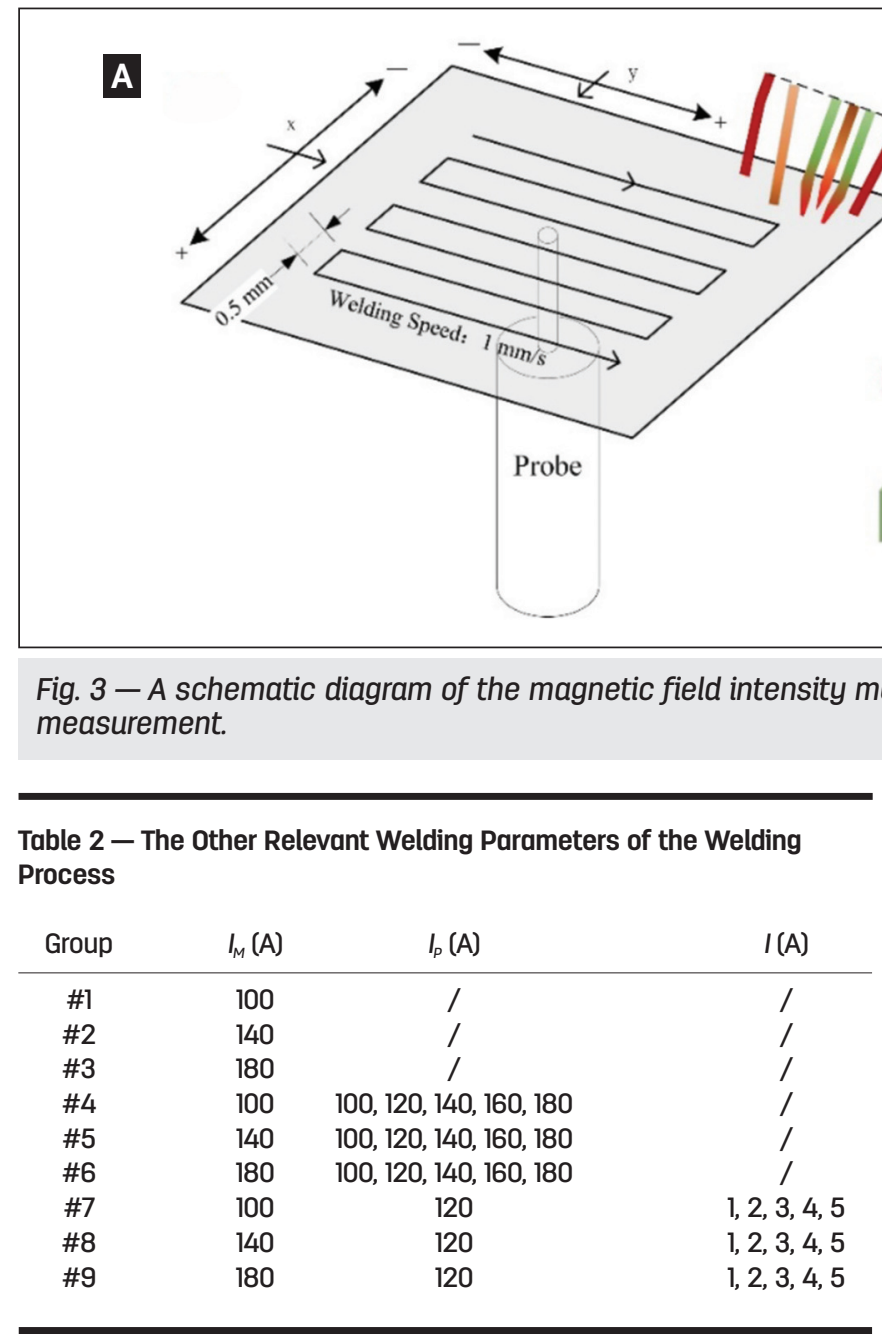

tail. The nozzle height was constant at $6 \mathrm{~mm}$. The welding speed was $5 \mathrm{~mm} / \mathrm{s}$. Pure argon was used as plasma shielding gas with $3 \mathrm{~L} / \mathrm{min}$ flow rate. The shielding gas was composed of argon (80 vol-\%) and carbon dioxide (20 vol-\%), and was chosen at a volume flow rate with $12 \mathrm{~L} / \mathrm{min}$ in all experiments. The other relevant welding parameters of the welding process are shown in Table 2, containing GMAW-P current $\left(I_{M}\right)$, plasma arc welding (PAW) current $\left(I_{P}\right)$, and magnetic field current $(I)$. The nozzle height was the distance from the PAW nozzle end to the workpiece surface.

As schematically shown in Fig. 2A-C, the image of the droplet transfer of single GMAW-P, plasma GMAW-P, and
plasma-GMAW-P under the action of a magnetic field were obtained to reveal the effect of the plasma arc and magnetic field on the droplet transfer. Compared to Fig. $2 \mathrm{~B}$ and $\mathrm{C}$, the plasma arc was biased to the wire due to the external magnetic field.

Teslameter was chosen to measure the magnetic field intensity. The schematic diagram of the magnetic inductance line measured by Teslameter is shown in Fig. 3A. As shown in Fig. 3A, the Teslameter was fixed under the torch during the measurement. The distance between the sensor probe and the plasma nozzle in the hybrid welding torch was 1 $\mathrm{mm}$. Figure $3 \mathrm{~B}$ is the schematic diagram of the magnetic inductance line measured by ferrous powder. To ensure the accuracy of the measurement results, the hybrid welding torch was placed about $3 \mathrm{~mm}$ above the ferrous powder in the measurement process. Before each measurement, the same amount of ferrous powder was uniformly measured by the balance and eventually spread on an A4 paper sheet. The specification of ferrous powder was 200 mesh.

\section{The Distribution of Magnetic Induction Lines}

The distribution of the magnetic field intensity and magnetic induction lines measured in the different magnetic currents by Teslameter and ferrous powder is shown in Fig. 4. It can be clearly seen from the diagrams that the intensity of transverse magnetic induction lines between the two 

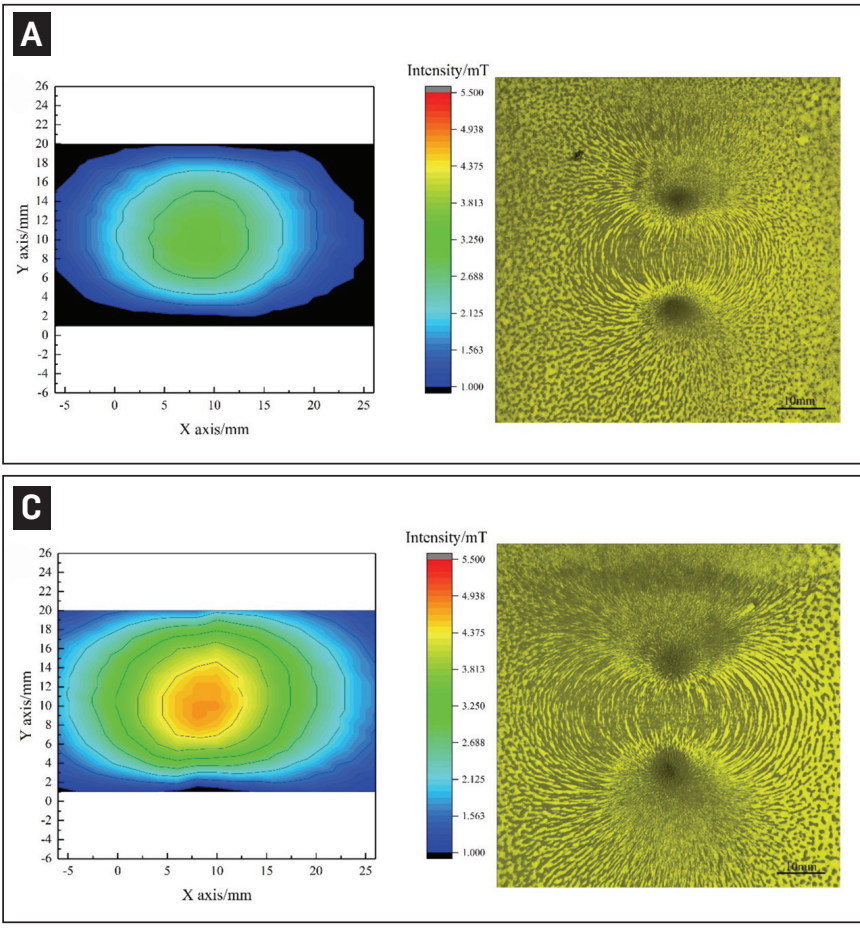

\section{$\mathbf{E}$}

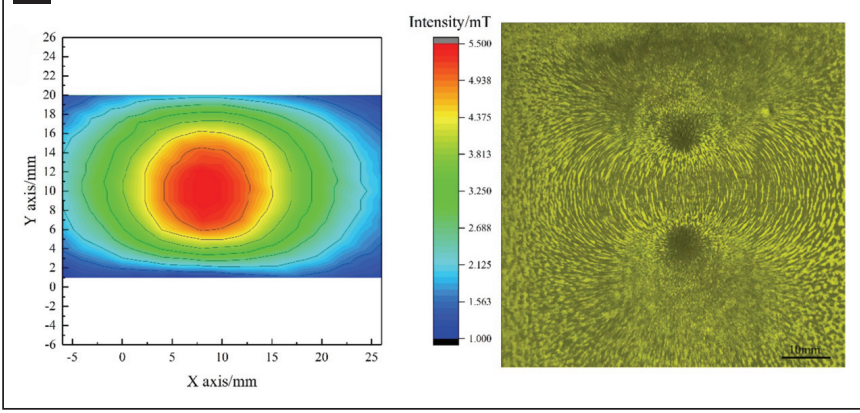

magnetic poles was denser with the increase in the magnetic field current.

\section{Forces on the Droplet of Plasma GMAW-P and Plasma-GMAW-P with a Magnetic Field}

The droplet transfer cycles include forming, detaching, falling, and entering into the molten pool finally. To explore the mechanism further, the forces acting on the droplet are illustrated in Fig. 3. Previous research indicated the forces acting on the droplet mainly include gravity $\left(F_{g}\right)$, plasma flow force $\left(F_{p}\right)$, electromagnetic pinch force $\left(F_{e m}\right)$, Lorentz force $(F)$, arc repulsive force $\left(F_{L}\right)$, surface tension $\left(F_{\sigma}\right)$, and spot force $\left(F_{s}\right)$. Gravity, plasma flow force, and electromagnetic pinch force could promote the droplet transfer among these forces. The schematic diagram of forces acting on the droplet of plasma GMAW-P or plasma GMAW-P hybrid welding with a magnetic field is shown in Fig. 5A and B, respectively.

1. Arc repulsive force, $F_{L}$

The polarity between PAW and GMAW-P is opposite,

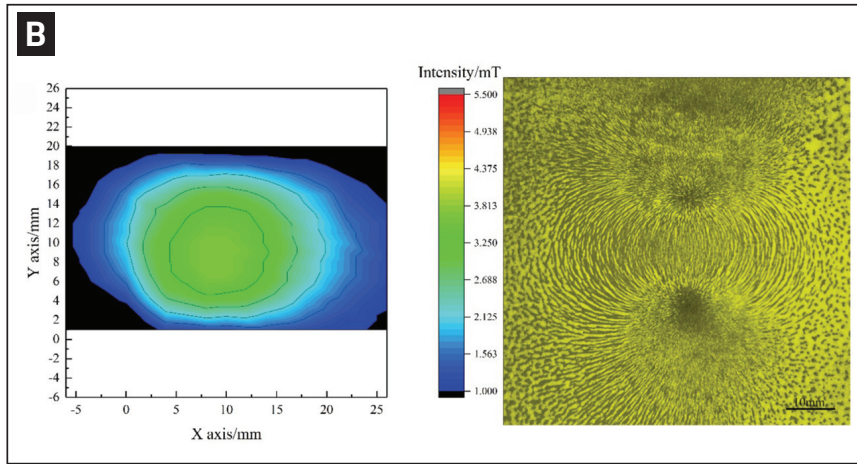

D

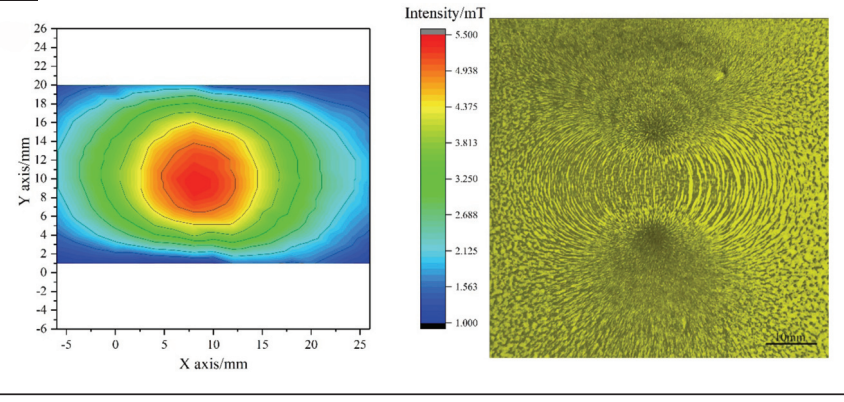

Fig. $4-A$ schematic diagram of the magnetic induction lines under different magnetic field currents: $A-1 A ; B-2 A ; C-$ $3 A ; D-4 A ; E-5 A$.

which produces arc repulsive force. Arc repulsive force can be expressed by Equation 1

$$
F_{L}=K \frac{I_{1} I_{2}}{L}
$$

where $I_{1}, I_{2}$, and $L$ are the plasma current, GMAW-P current, and distance between plasma axis tungsten and wire, respectively. $K$ is coefficient ( $K=\mu / 4 \pi, \mu$ is dielectric permeability).

\section{Gravity, $F_{g}$}

The gravity acting on the droplets can be represented by Equation 2

$$
F_{g}=\frac{4}{3} \pi R^{3} \rho g
$$

where $R, \rho$, and $g$ represent the droplet radius, droplet density, and gravity acceleration, respectively. Therefore, the gravitational force is proportional to the diameter of the droplet from the formula and vertical downward, so it can be considered that the force always promotes the droplet transfer in the welding process.

\section{Plasma flow force, $F_{p}$}

The plasma flow force plays a significant role in the process of the detachment of droplets, which can be shown by Equation 3

$$
F_{p}=\frac{C_{d} A_{p} \rho_{f} v_{f}^{2}}{2}
$$

where $C_{d}, A_{p}, \rho_{f}$, and $v_{f}$ are the plasma flow coefficient, the ac- 

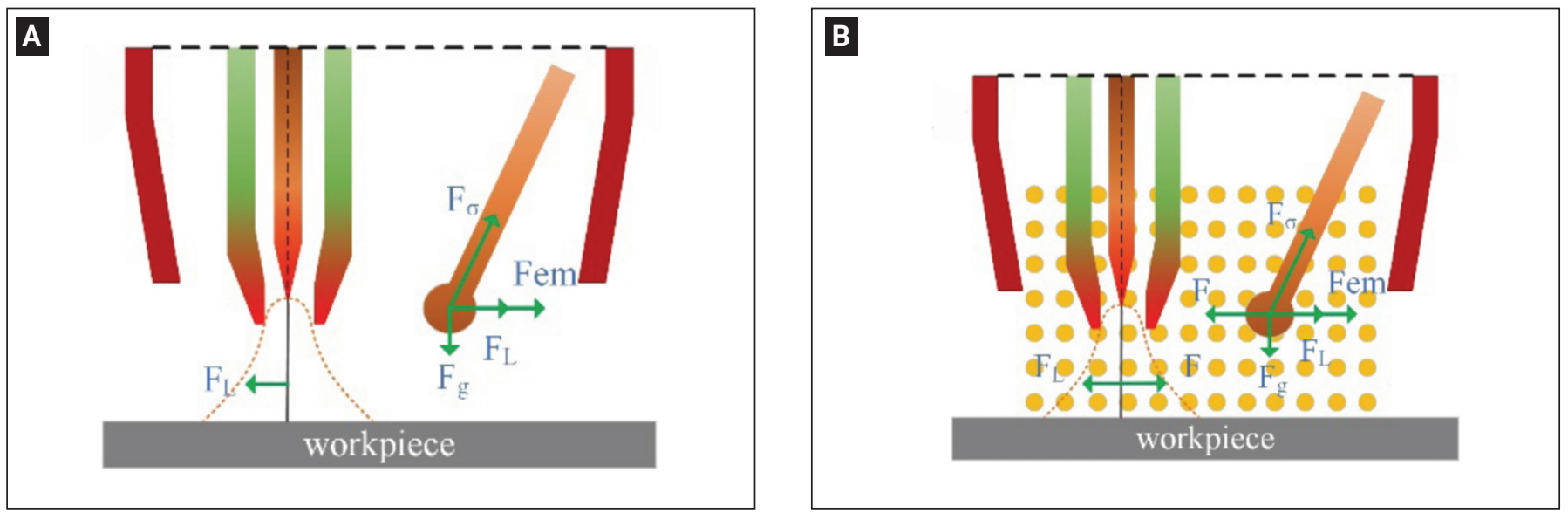

Fig. 5 - Forces acting on the droplet under different hybrid welding processes: $A$ - Plasma GMAW-P hybrid welding; $B$ - plasmaGMAW-P hybrid welding with a magnetic field.

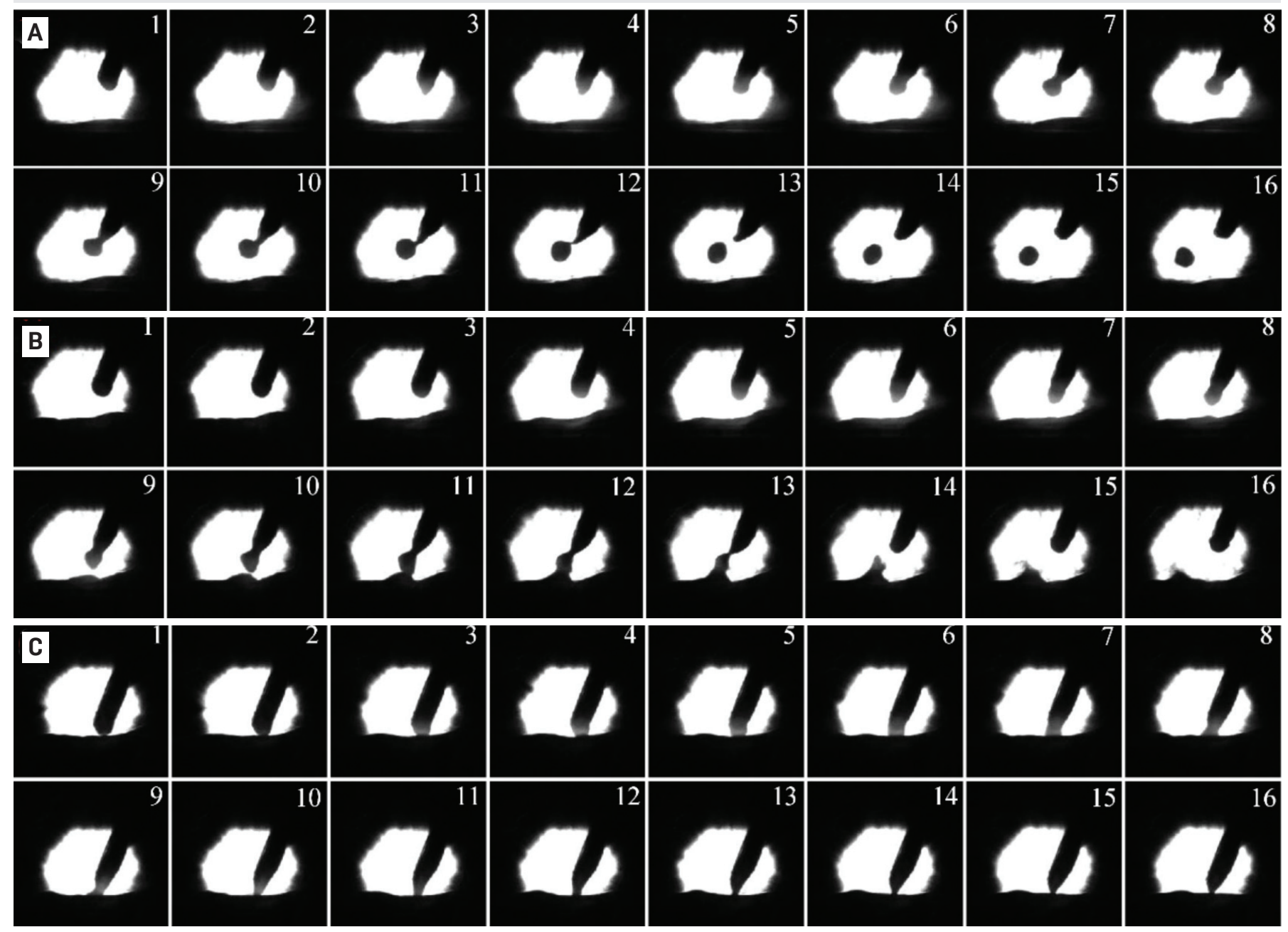

Fig. 6 - Successive high-speed camera images at a different GMAW currents in single GMAW-P: A - 100 A; B - 140 A; C - 180 A (frames/0.25 ms).

tion area of the plasma flow, the density of the plasma flow, and the velocity of the plasma flow, respectively. And $C_{d}=0.45$.

\section{Surface tension, $F_{\sigma}$}

The surface tension acting on the droplets can be ex- pressed by Equation 4

$$
F_{\sigma}=2 \pi \gamma_{w} \gamma e_{w}
$$

where $\gamma_{w}, \gamma$, and $e_{w}$ are the radius of the wire, surface tension coefficient, and unit vector in the wire direction, respective- 

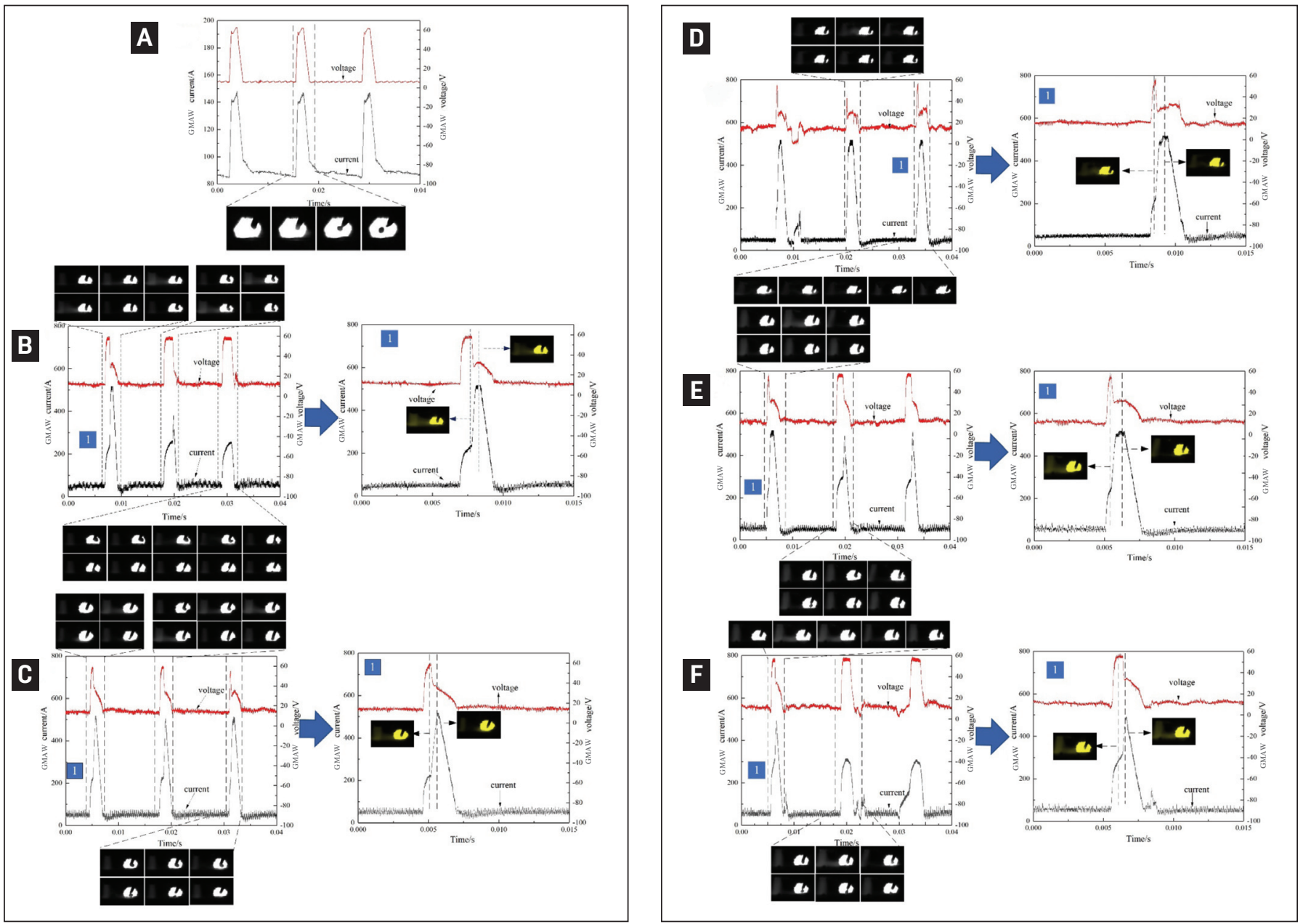

Fig. 7-Droplet transfer and electrical signal curve of GMAW at different plasma welding currents with constant GMAW of 100 A: $A$ -0 A; B - 100 A; C - 120 A; D - 140 A; E - 160 A; F - 180 A.

ly. Additionally, surface tension impedes the droplet detaching from the wire.

5. Electromagnetic pinch force, $F_{e m}$

The electromagnetic pinch force can be expressed by Equation 5

$$
F_{e m}=\frac{\mu_{0} I^{2}}{4 \pi}\left\{-\left[\begin{array}{l}
\frac{1}{4}-\ln \left(\frac{r_{d} \sin \theta}{r_{w}}\right)+\frac{1}{1-\cos \theta} \\
-\frac{2}{(1-\cos \theta)^{2}} \ln \left(\frac{2}{1+\cos \theta}\right)
\end{array}\right]\right\}
$$

where $\mu_{0}, I, r_{d}, r_{w}$, and $\theta$ are the permeability of free space, welding current, droplet radius, wire radius, and arc hanging angle, respectively.

\section{Lorentz force, $F$}

Lorentz force is produced under the action of the external transverse magnetic field and the force could promote the coupling between the plasma and gas metal arc, which can be expressed by the following equation

$$
F=B q v
$$

7. Spot force, $F_{s}$

Spots are formed at the end of the welding wire in the welding process. The impact of the electron flow and the reaction force of the metal vapor at the cathode or anode spot causes pressure.

\section{Results and Discussion}

To certify the effect of the plasma arc and magnetic field intensity on droplet transfer in the hybrid welding process, successive droplet transfer images of single GMAW-P, plasma GMAW-P hybrid welding, and plasma-GMAW-P hybrid welding with a magnetic field were obtained with the aforementioned welding parameters in Table 2, respectively.

\section{Droplet Transition of Single GMAW-P}

Figure 6 illustrates the successive high-speed camera images in one pulse period of droplet transfer in the single 
A

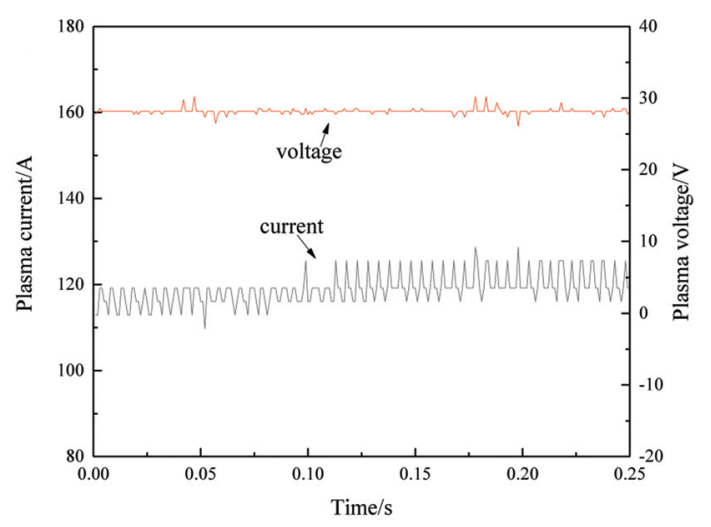

B

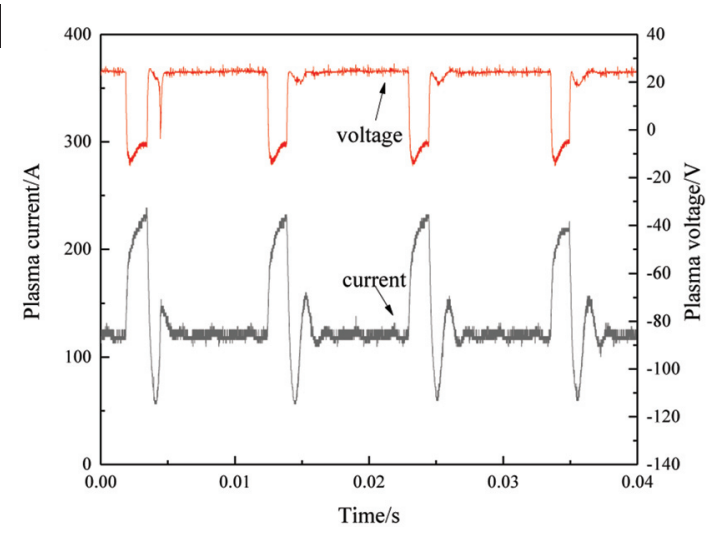

Fig. 8 - Schematic diagram of the electrical signal curve of PAW in plasma GMAW-P hybrid welding with a constant plasma welding current of $120 \mathrm{~A}$ under different GMAW currents: $A-0 \mathrm{~A} ; \mathrm{B}-100 \mathrm{~A}$.
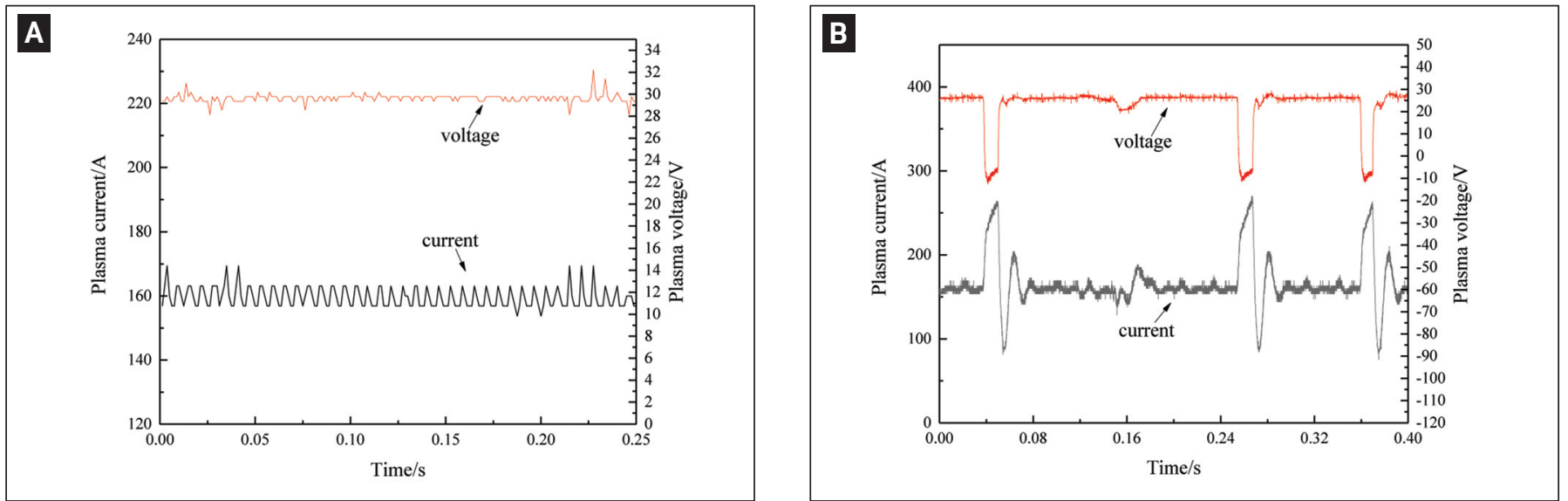

Fig. 9-Schematic diagram of the electrical signal curve of PAW in plasma GMAW-P hybrid welding with a constant plasma welding current of $160 \mathrm{~A}$ under different GMAW currents: $A-O A ; B-100 \mathrm{~A}$.

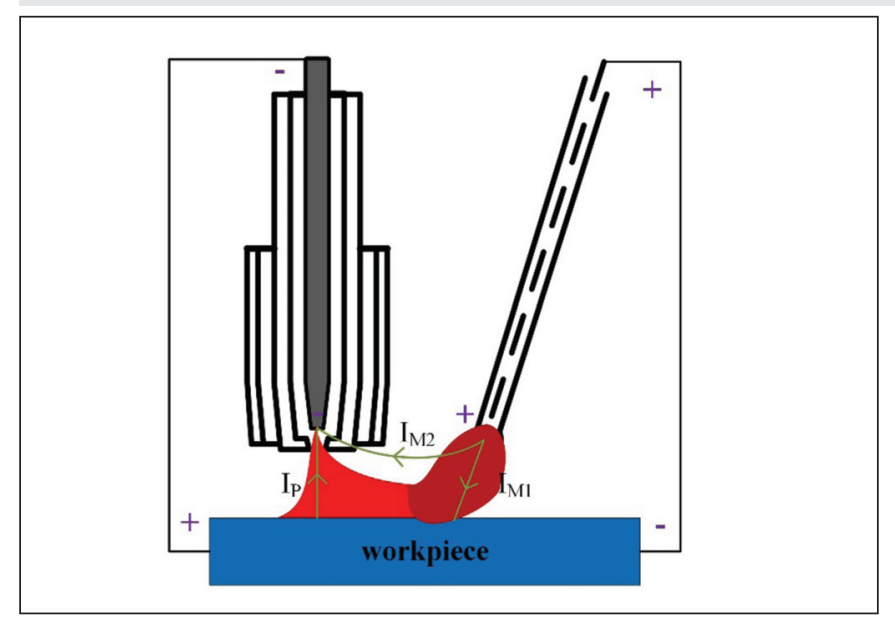

Fig. 10 - Schematic diagram of shunt at the GMAW current.

GMAW-P process with the first to third sets of welding parameters in Table 2. Apparently, Fig. 6A shows a projected transfer was formed when the GMAW current was $100 \mathrm{~A}$. When the GMAW current increased to $180 \mathrm{~A}$, spray transfer was observed as shown in Fig. 6C. The GMAW current of $140 \mathrm{~A}$ was considered as a critical current for the droplet transfer from projected to spray transfer as shown in Fig. $6 \mathrm{~B}$.

\section{Droplet Transfer of GMAW in Plasma-GMAW-P Hybrid Welding}

Successive high-speed camera images of the droplet transfer at different GMAW and plasma welding currents with fourth to sixth sets of welding parameters in Table 2 were obtained in plasma GMAW-P hybrid welding and the effect of the plasma arc on the droplet transfer was investigated by comparing with Fig. 6 .

\section{Droplet Transfer of GMAW under a Constant GMAW Current of $100 \mathrm{~A}$}

The schematic diagram of successive high-speed camera images and voltage-current waveform curves of GMAW at different plasma welding currents under the constant GMAW current of $100 \mathrm{~A}$ in the plasma GMAW-P hybrid process are shown in Fig. 7. Figure 7A shows the droplet transfer and voltage-current waveform curves at a single GMAW-P current of $100 \mathrm{~A}$. As shown in Fig. 7A, one- 

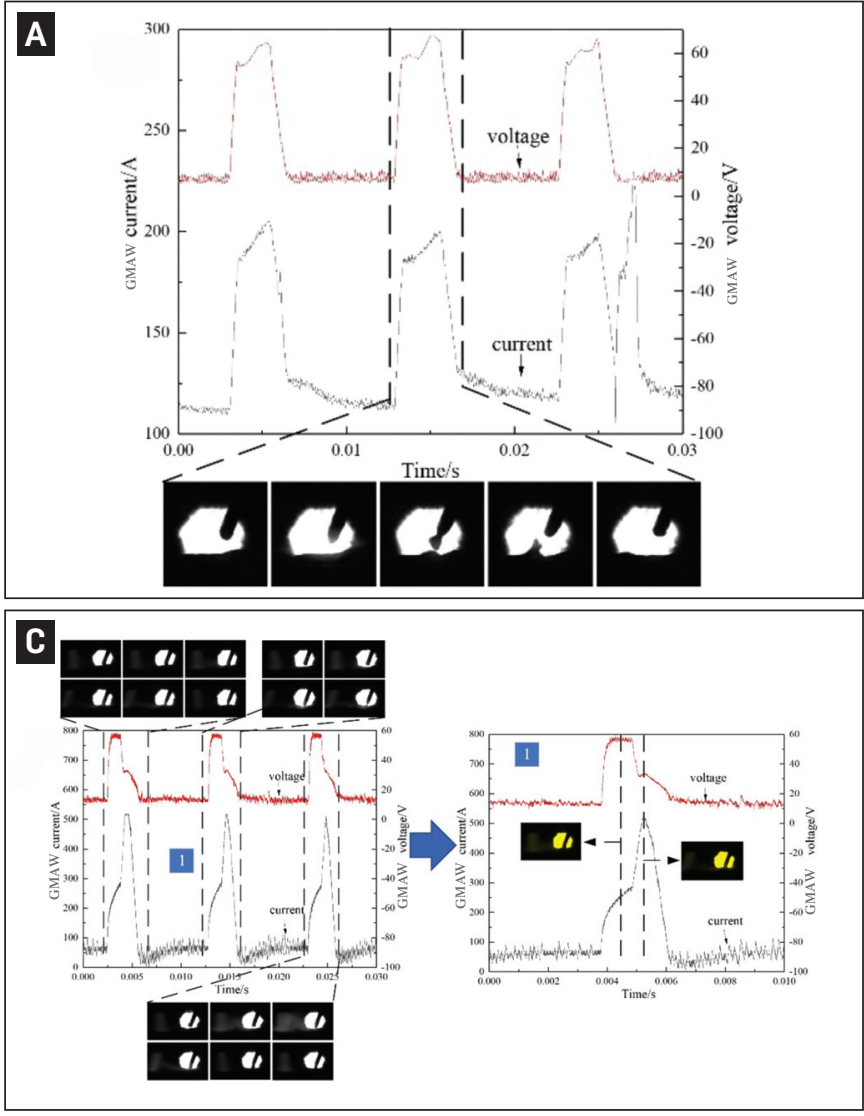

$\mathbf{E}$

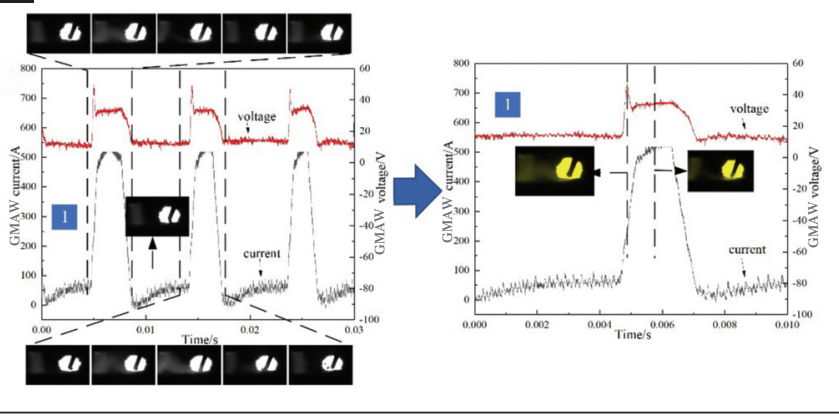

B
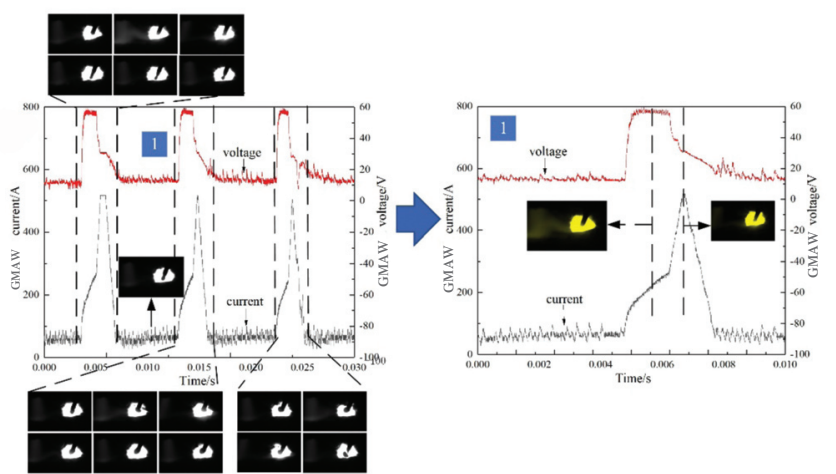

D

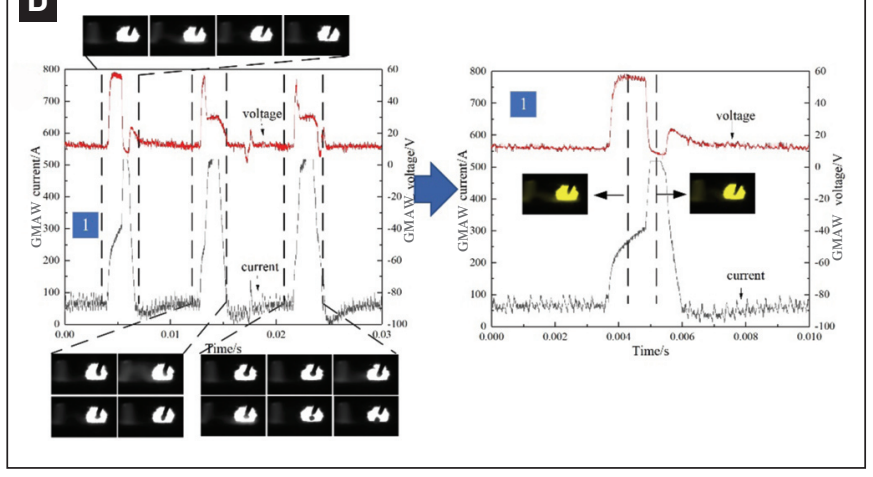

$\mathbf{F}$

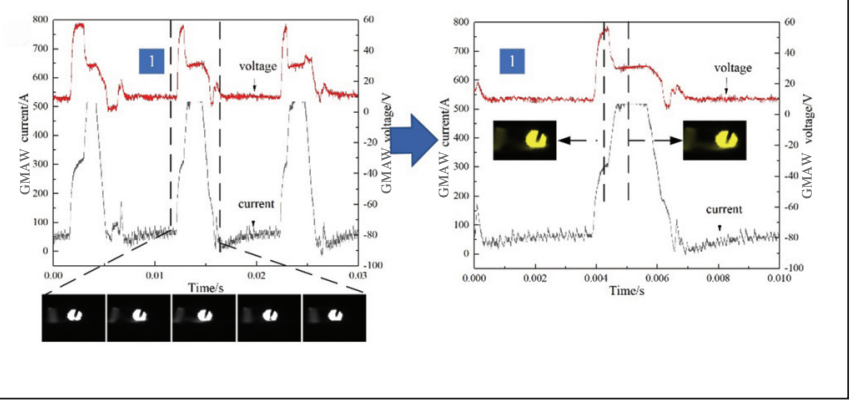

Fig. 11 - Droplet transfer and the electrical signal curve of GMAW at different plasma welding currents with constant GMAW of 140 A: $A-0$ A; B 100 A; C - 120 A; D - 140 A; E - 160 A; F - 180 A.

droplet-per-pulse projected transfer was typically sketched in the single GMAW-P in which the droplet was starting gradually to aggregate and grow, forming a necking at the wire tip in the pulse stage to promote the droplet separate from the wire tip, then fallen into the molten pool in the direction of the wire.

Successive high-speed camera images and voltage-current waveform curves of the droplet transfer were acquired in Fig. 7B-F, which fixed on the GMAW current of $100 \mathrm{~A}$ and $\mathrm{a}$ varied plasma current from 100 to $180 \mathrm{~A}$ with 20-A intervals, respectively. Compared with Fig. 7A, due to the existence of the plasma arc, the droplet transfer process and waveform curves of GMAW from Fig. 7B to F were changed. First, the droplet transfer mode was transformed from one drop, one pulse to several pulses one-drop and transfer period were increased. The changed voltage-current waveform curves were observed as follows: There was no obvious change of curves in the pulse base phase of the GMAW current because of the straight resistance of the plasma arc led to the uncoupling of the plasma and gas metal arc. However, the pulse peak current increased significantly in the pulse peak phase of the GMAW current. Whereas, the pulse peak voltage was changed slightly. Meanwhile, as seen in Fig. $7 \mathrm{~B}-\mathrm{F}$, when the voltage was in the pulse peak phase, the current waveform appeared at a slow increase. When the current was in the pulse peak phase, the voltage waveform appeared at a slow decrease. Most importantly, the plasma and gas metal arc was connected to form an indirect arc with the enlargement of the gas metal column in the pulse stage, regardless of the change of current or voltage waveform.

To explore the function of the indirect arc, the voltagecurrent waveform curves of the plasma arc of fixing on the 
$\mathbf{A}$

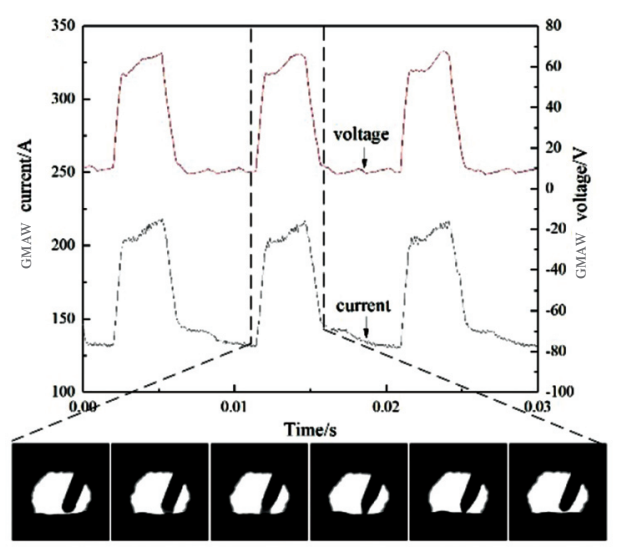

C

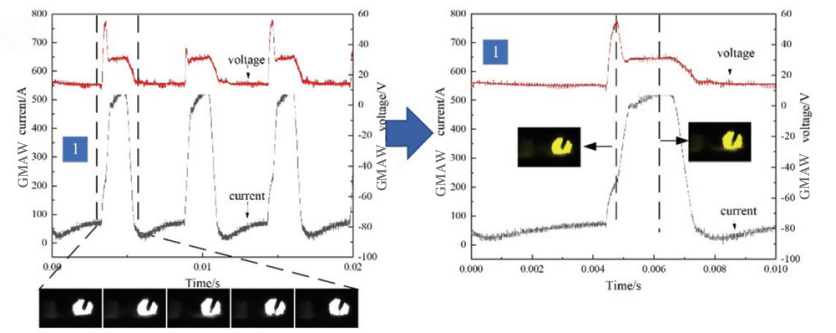

$\mathbf{E}$

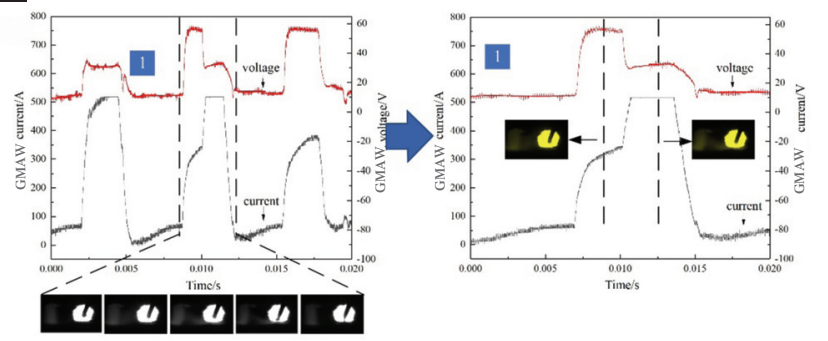

B

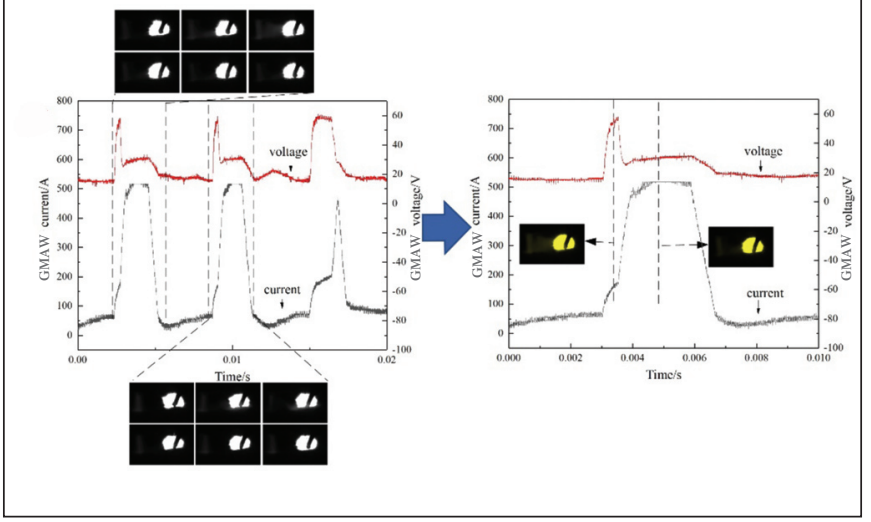

D

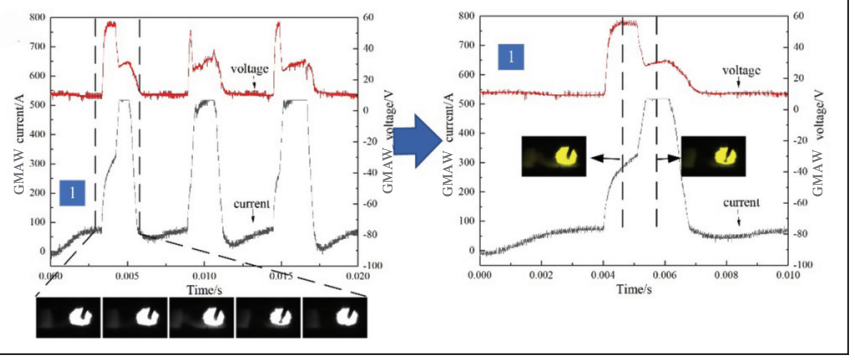

$\mathbf{F}$

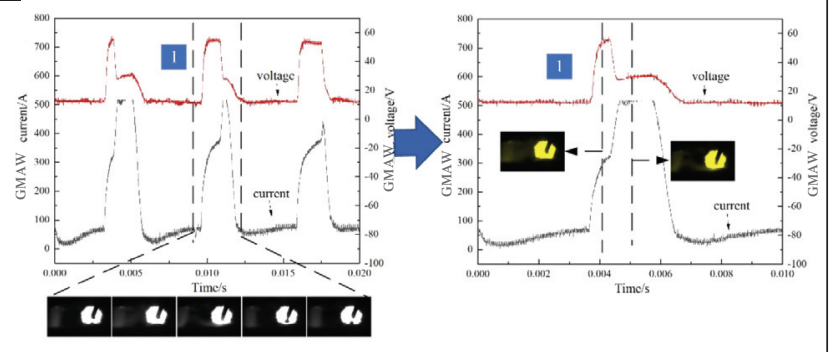

Fig. 12 - Droplet transfer and electrical signal curve of GMAW at different plasma welding currents with constant GMAW at 180 A: $A-0 A ; B-100 A ; C-120 A ; D-140 A ; E-160 A ; F-180 A$.

GMAW current of $100 \mathrm{~A}$ and varied plasma welding current of 120 and $160 \mathrm{~A}$ in plasma GMAW-P hybrid welding were shown in Figs. 8 and 9, respectively. The plasma welding current increased in the period of the indirect arc. Therefore, due to the GMAW current, a shunt phenomenon emerged in the indirect arc stage. The GMAW current is divided into two parts in Fig. 10. One part of the GMAW current formed between the wire and workpiece. Another part of the GMAW current formed between the wire and plasma arc. In this case, the shunt of the GMAW current caused the slow increase in the plasma welding current in the pulse phase in Figs. 8B and 9B.When the GMAW current reached the pulse peak in Fig. 7B-F, the slow decrease of the voltage waveform was possible that the increase of the GMAW current enhanced the repulsive force from two arcs, making the plasma arc move away from the gas metal arc. Therefore, the coupling degree and the divided GMAW current between the wire and plasma arc was reduced, which caused the decrease in voltage. In other words, the plasma arc had a significant effect on voltage-current waveform curves of GMAW, and the droplet transfer was transformed into repelled transfer due to the introduction of the plasma arc.

As seen in Fig. 7B and C, when the plasma welding current was 100 and $120 \mathrm{~A}$, the formed droplet didn't break away from the wire tip after the first pulse phase. This may be attributed to shunt, which resulted in less welding current and less heat between the wire and workpiece. At this moment, surface tension in the droplet was greater than gravity. After the second and third pulse phase, the droplet continued to aggregate and grow to form a larger droplet to detach the wire because gravity was greater than surface tension, forming several pulse one-drop repelled transfers. However, as seen in Fig. 7D-F, the droplet detached from the wire tip after two pulse phases when the plasma welding current increased to 140,160 , and $180 \mathrm{~A}$, respectively. This was possible in that the size of the plasma arc column and overlapping region of the plasma and gas metal arc was increased larger with the improvement of the plasma welding current, resulting in the stronger electromagnetic pinch force acting on the droplet. The surrounding temper- 


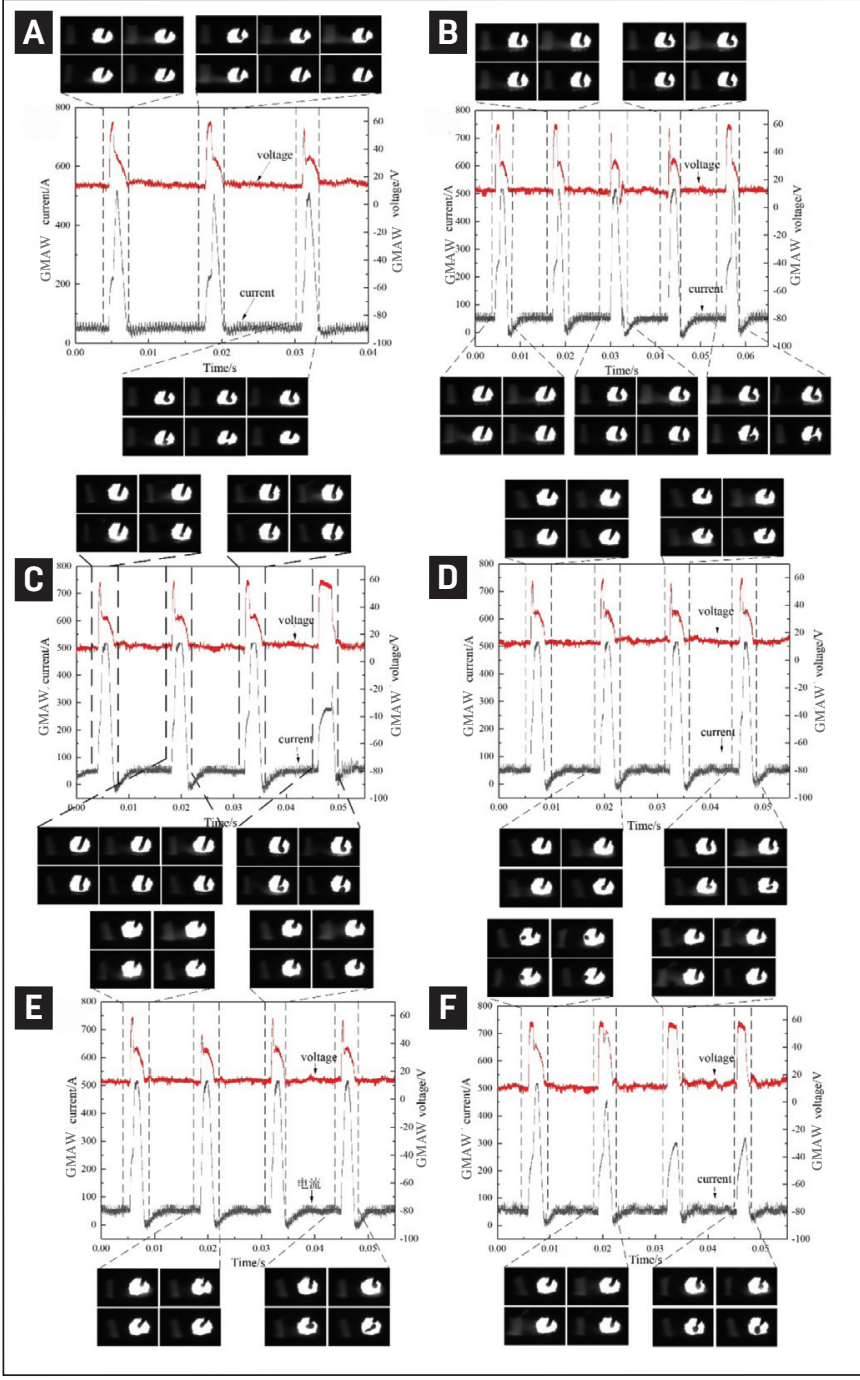

Fig. 13 - Droplet transfer and electrical signal curve of plasmaGMAW-P with different magnetic field currents in Experiment 7: $A-0 A ; B-1 A ; C-2 A ; D-3 A ; E-4 A ; F-5 A$.

ature in the droplet was enhanced dramatically with the increase in the plasma welding current, which improved the preheating function for the wire. Therefore, the period of droplet transfer was decreased with the increase in the plasma welding current.

As shown in Fig. 7, when the plasma welding current was increased, the droplet was located on the right side of the wire. This phenomenon may be attributed to the increase of the plasma welding current enhanced arc repulsive force, $F_{L}$, between the plasma and gas metal arc in Fig. 5 .

\section{Droplet Transfer of GMAW under a Constant GMAW Current of 140 A}

The successive high-speed camera images and voltagecurrent waveform curves of GMAW at a different plasma welding current under a constant GMAW current of $180 \mathrm{~A}$ in plasma GMAW-P hybrid welding are sketched in Fig. 11. The voltage-current waveform curves in Fig. 11 are similar to Fig. 7 with the slow variation in the stage of the indirect

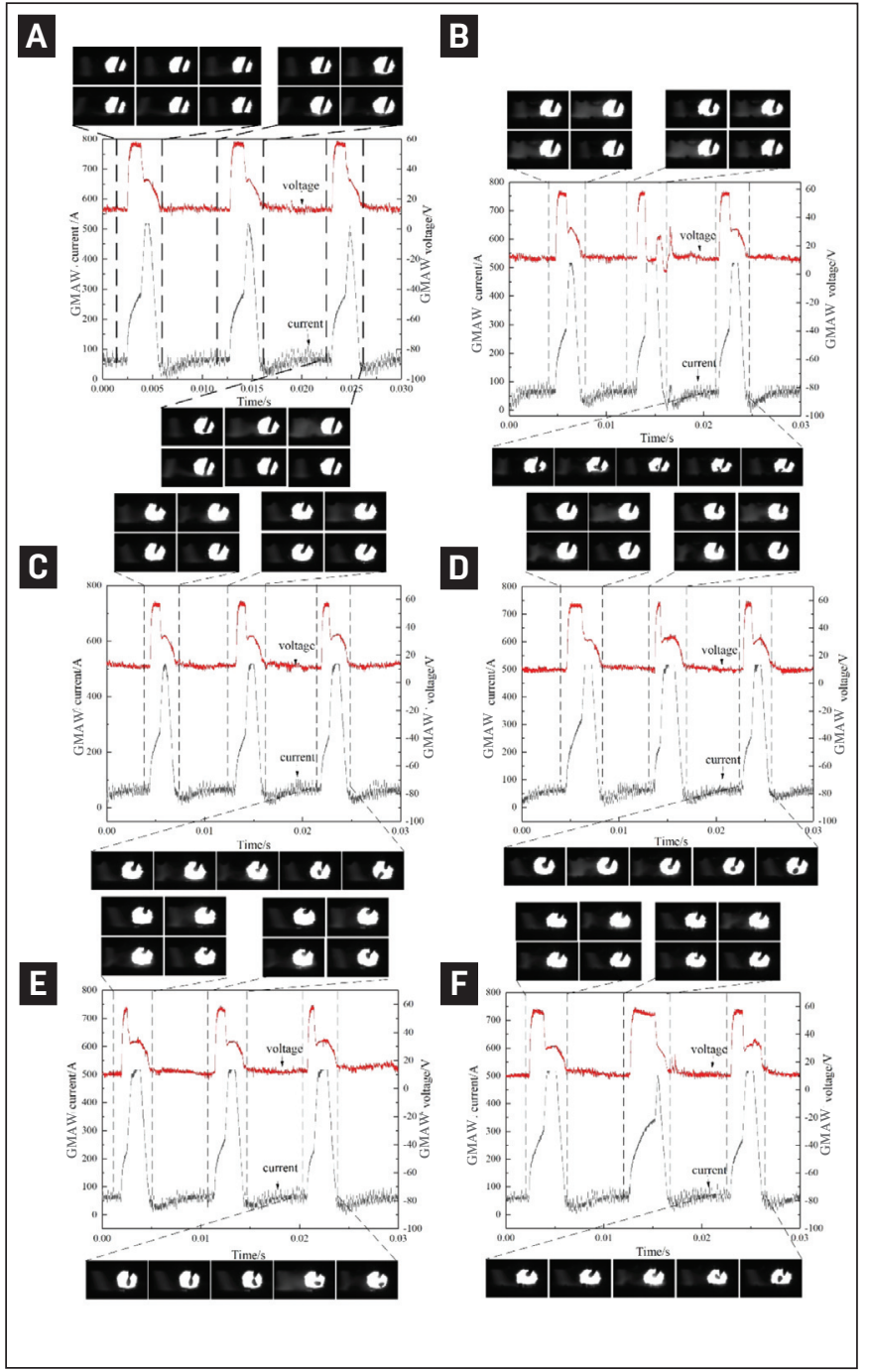

Fig. 14 - Droplet transfer and electrical signal curve of plasmaGMAW-P with different magnetic field currents in Experiment 8 : $A-0 A ; B-1 A ; C-2 A ; D-3 A ; E-4 A ; F-5 A$.

arc. As shown in Fig. 11A, the metal transfer mode under a constant welding current of $140 \mathrm{~A}$ in single GMAW-P is one droplet per pulse droplet transfer. The droplet transfer mode of GMAW was obviously changed due to the presence of the plasma arc from Fig. 11B-F. The droplet transfer mode was transformed into several pulse one-drop repelled transfer when the plasma welding current was less than 160 A, ascribing the shunt phenomenon of the GMAW current with the increase in the GMAW current. However, droplet transfer cycles were reduced with the improvement in the plasma welding current. The droplet-transfer form was transformed into one pulse, one drop projected transfer when the plasma welding current exceeded 160 A. This may be because the increased plasma and GMAW current improved the surrounding temperature around the wire and promoted the melting of the wire.

The position of the detaching droplet was mainly located in the direction of the wire and below, comparing Figs. 7 and 11. This was mainly because even if the arc repulsive force, $F_{L}$, was increased with the introduction of the plasma cur- 
A

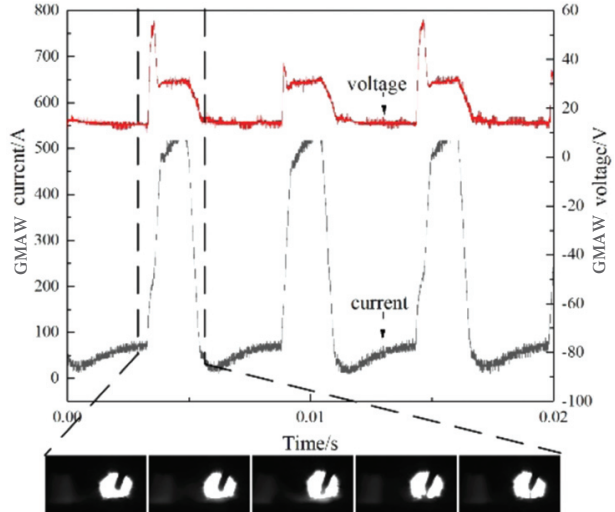

C

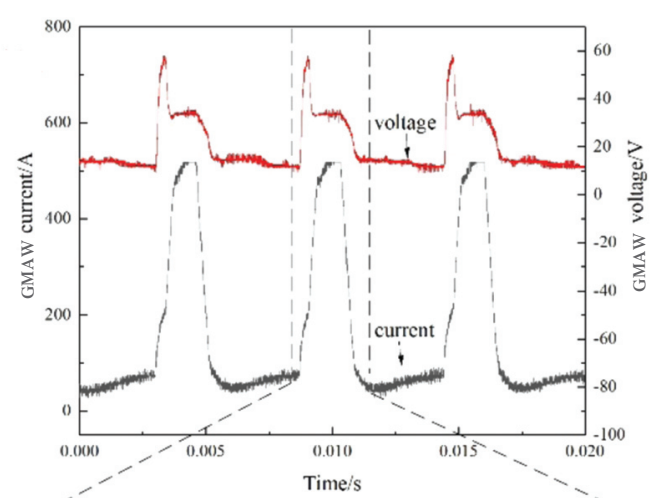

\section{\begin{tabular}{llll|l|l|l}
$\boldsymbol{0}$ & $\boldsymbol{0}$ & $\boldsymbol{0}$ & $\boldsymbol{\omega}$ & $\boldsymbol{0}$
\end{tabular}}

$\mathbf{E}$

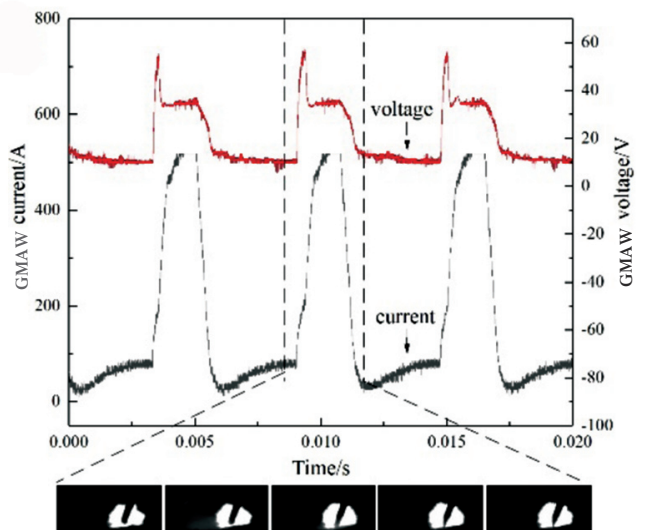

Fig. 15 - Droplet transfer and electrical signal curve of plasma-GMAW-P with different magnetic field currents in Experiment 9: A $-O A ; B-1 A ; C-2 A ; D-3 A ; E-4 A ; F-5 A$.

rent, the arc column of GMAW-P was enhanced largely with the increase in the GMAW current.

\section{Droplet Transfer of GMAW under a Constant GMAW Current of 180 A}

The successive high-speed camera images and voltagecurrent waveform curves of GMAW at different plasma weld-
B

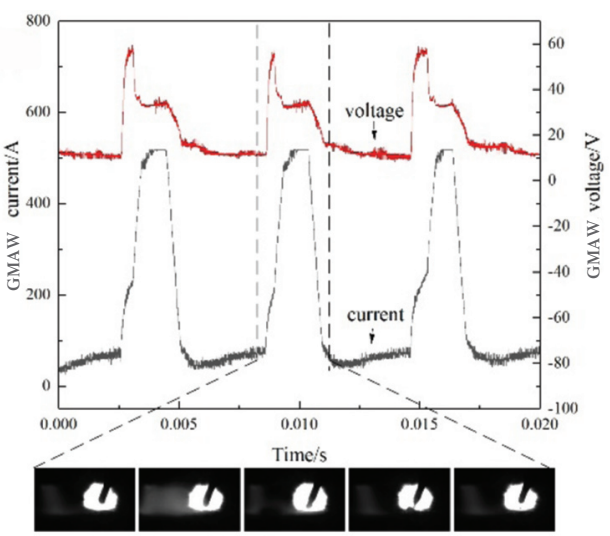

D

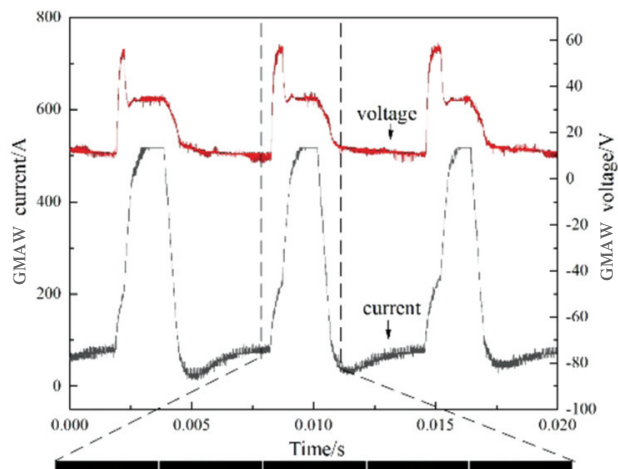

\begin{tabular}{ll|l|l|l|}
6 & 6 & 6 & 4 & 6
\end{tabular}

$\mathbf{F}$

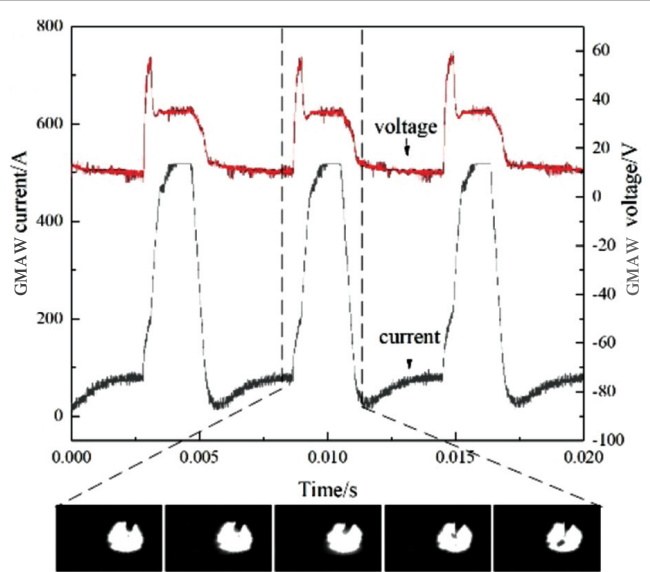

ing currents under a constant GMAW current of $180 \mathrm{~A}$ in plasma GMAW-P hybrid welding is shown in Fig. 12. The voltagecurrent waveform curves in Fig. 12 are similar to Fig. 7, appearing as the slow variation in the indirect arc stage, as well. As shown in Fig. 12, the droplet transfer period is several pulses with a plasma welding current of $100 \mathrm{~A}$. However, the transfer period was one pulse when the plasma welding current exceeded $100 \mathrm{~A}$. Besides, the droplet transfer mode is 


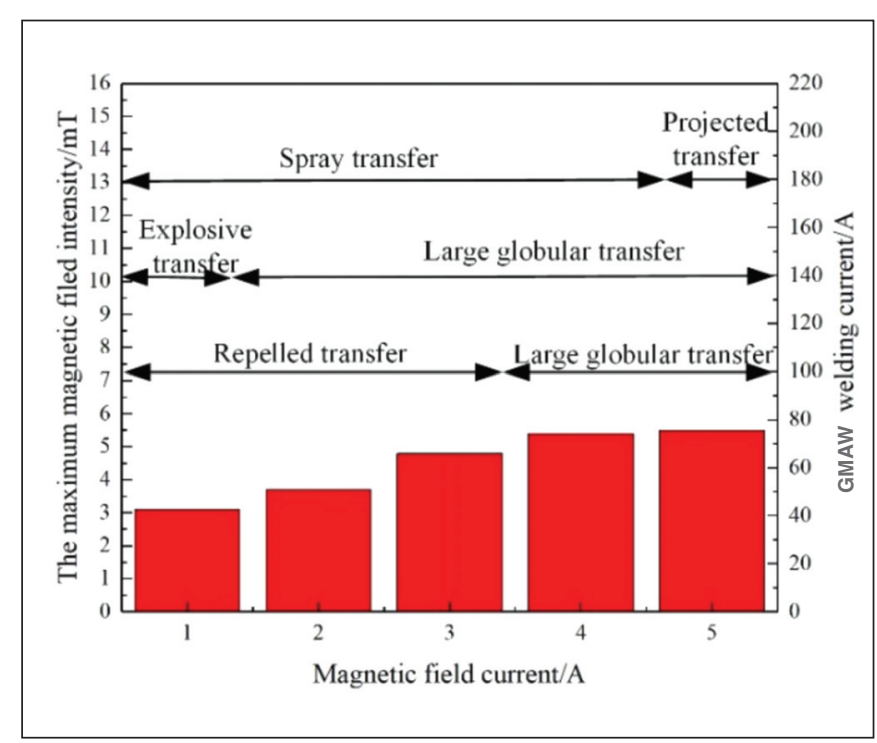

Fig. 16 - Schematic diagram of the relationship between magnetic field intensity and droplet transfer with different GMAW currents fixed on the plasma welding current of $120 \mathrm{~A}$.

spray transfer in Fig. 12A and B. The droplet transfer mode was transformed to the typical projected transfer when the plasma welding current was more than $100 \mathrm{~A}$. The reasons were as follows: First, the enlarged shunt phenomenon raised the heat input between the wire and workpiece due to the improvement in the GMAW current. Second, the coupling region was increased due to the enhanced plasma welding current, which improved the surrounding temperature around the wire. Above all, the wire was melted quickly and formed one pulse, one droplet projected transfer.

The detaching droplet is mainly located in the direction of the wire as shown in Figs. 8 and 11. The phenomenon was mainly because even if the arc repulsive force, $F_{L}$, was increased due to the plasma welding current, the gas metal arc column and coupling region were enhanced largely due to the increased welding current. As a result, the electromagnetic pinch force was improved greater than repulsive force.

\section{Droplet Transfer of Plasma-GMAW-P with a Magnetic Field}

To study the effect of the magnetic field on droplet transfer, successive high-speed camera images and voltagecurrent waveform curves of the droplet transfer with a GMAW current of 100,140, and $180 \mathrm{~A}$ under a constant plasma welding current of $120 \mathrm{~A}$ in plasma-GMAW-P hybrid welding with seventh to ninth sets of welding parameters in Table 2 are obtained in Figs. 13-15, respectively. It was found that the period of the indirect arc was improved slightly under the action of the external magnetic field.

\section{Droplet Transfer of GMAW under a Constant GMAW Current of $100 \mathrm{~A}$}

Figure 13 shows the droplet transfer and voltage-current waveform curves of GMAW with a fixed plasma welding current of $120 \mathrm{~A}$ and GMAW current of $100 \mathrm{~A}$ with a varying magnetic field current from 0 to $5 \mathrm{~A}$ with 1-A intervals in plasma-GMAW-P hybrid welding with a magnetic field. In the plasma-GMAW-P with a magnetic field hybrid process, it was found that the voltage-current waveform curves of GMAW only slightly changed under the different magnetic field currents by comparison due to the indirect arc in Fig. 13, but the droplet transfer mode was still several pulses per drop. In addition, the droplet transfer mode, droplet transfer period, detaching location of the droplet from the wire, and arc monopoly had magnitude changes at a certain range. First, whether the GMAW current was in the pulse peak phase or pulse base phase, the plasma arc was inclined to wire tip as the result of the Lorentz force generated by the external magnetic field, which could better preheat the wire.

Nevertheless, the droplet transfer period was increased slightly under the action of the external magnetic field. This may be because the inclined plasma arc improved the time of the indirect arc, and the shunt time of the GMAW current was increased in the magnetic field, which reduced the current between the wire and workpiece. When the magnetic field current was less than $3 \mathrm{~A}$, a repelled transfer was formed in the wire tip and the detaching position of the droplet was located on the right side of the wire. The phenomenon may be attributed to the fact that the Lorentz force was less than the repulsive force between the plasma and gas metal arcs even though the magnetic field current was improved. Large globular transfer was formed in the wire tip when the magnetic field current increased above $3 \mathrm{~A}$. Simultaneously, the detaching position of the droplet was located on the left side or in the direction of the wire. This may be because the Lorentz force was significantly improved in the magnetic field, slightly greater than or equal to the repulsive force between the plasma and gas metal arcs.

\section{Droplet Transfer of GMAW under a Constant GMAW Current of 140 A}

Figure 14 shows the droplet transfer and voltage-current waveform curves of GMAW with a fixed plasma welding current of $120 \mathrm{~A}$, GMAW current of $140 \mathrm{~A}$, and varying magnetic field currents from 0 to $5 \mathrm{~A}$ with 1-A intervals in plasmaGMAW-P hybrid welding with a magnetic field. As seen in Fig. 14 , the plasma arc is still inclined to the wire tip as the result of the Lorentz force generated by the external magnetic field. However, the droplet transfer period was not changed, which may be because the increased GMAW current generated enough heat to melt the wire. Besides, the droplet transfer was explosive transfer when the magnetic field current was $1 \mathrm{~A}$. When the magnetic current exceeded $1 \mathrm{~A}$, the droplet transfer was large globular transfer. This may be because the inclined plasma arc under a magnetic field could preheat the wire, and the increase of the GMAW current generated larger arc heat, which formed free transition. Nevertheless, the detaching position of the droplet was also located on the left side or in the direction of the wire, which was attributed to the enhancement of the GMAW current.

\section{Droplet Transfer of GMAW under Constant GMAW Current of 180 A}

Figure 15 shows the droplet transfer and voltage-current 
waveform curves of GMAW with a fixed plasma welding current of $120 \mathrm{~A}, \mathrm{GMAW}$ current of $180 \mathrm{~A}$, and varying magnetic field currents from 0 to $5 \mathrm{~A}$ with 1 -A intervals in plasma-GMAW-P hybrid welding.

The droplet transfer period under the external magnetic field was similar to that without the magnetic field. The droplet transfer was spray transfer when the magnetic field current was less than $5 \mathrm{~A}$. However, the droplet transfer was projected transfer when the magnetic field current increased to $5 \mathrm{~A}$. This may be because magnetic field intensity was enlarged with the increase in the magnetic field current, which improved the Lorentz force in Fig. 5B.

Under the action of the magnetic field, the plasma arc still inclines to the welding wire, and the inclination depends on the magnetic field strength.

The plasma arc was still inclined to the wire under the action of the magnetic field, and the inclination degree was dependent on magnetic field intensity. When the magnetic field current was $5 \mathrm{~A}$, the plasma arc was inclined at the largest degree. As a result, the period of the shunt phenomenon was enlarged in the indirect arc phase and the heat input into the workpiece was reduced, thus forming projected transfer. The falling droplets entered into the molten pool along the direction of the wire. This may be because the GMAW current was too large and generated lots of heat input and was less affected by the magnetic field and plasma arc.

Above all, when the plasma welding current was $120 \mathrm{~A}$, the relationship between the maximum magnetic field intensity and droplet transfer at different GMAW currents is presented in Fig. 16. Obviously, the droplet transfer under the different GMAW current was transformed for the introduction of the magnetic field, and there was a clear difference in the changing degree of the droplet transfer under different GMAW currents. The droplet transfer was changed from repelled transfer to large globular transfer when the magnetic field and GMAW current was 3 and 100 A, respectively. The large globular transfer was formed with the GMAW current of 140 A when the magnetic field current exceeded $1 \mathrm{~A}$. The droplet transfer was transformed from spray transfer to projected transfer with the GMAW current of $180 \mathrm{~A}$ when the magnetic field current increased to $5 \mathrm{~A}$.

\section{Conclusions}

The following conclusions were obtained as follows:

1) The droplet transfer and voltage-current waveform curves of GMAW in single GMAW-P, plasma GMAW-P hybrid welding, and plasma-GMAW-P hybrid welding with a magnetic field, respectively, were investigated in this research. The external magnetic field and plasma arc had significant effect on the droplet transfer by comparison.

2) The indirect arc of the plasma and gas metal arc emerged in the pulse peak phase of GMAW, forming the following phenomenon: When the voltage was in the pulse peak phase, the current waveform appeared at a slow increase. When the current was in the pulse peak phase, the voltage waveform appeared at a slow decrease. It was certified that the GMAW current was divided into two parts in the indirect arc stage. One part of the GMAW current formed between the wire and the workpiece. Another part of the GMAW current formed between the wire and plasma arc.

3) Compared to the droplet transfer and voltage-current waveform curves of GMAW in single GMAW-P and plasma GMAW-P hybrid welding, the plasma arc could transform the droplet transfer period, droplet transfer mode, and detaching position of the droplet. When the GMAW current wasn't more than $140 \mathrm{~A}$, the form and period of the droplet transfer was several pulse one-drop free transfers. The droplet transfer period was decreased with the increase in the plasma welding current. When the GMAW current exceeded $140 \mathrm{~A}$ and the plasma welding current was less than 180 A, droplet transfer was spray transfer. Droplet transfer was transformed into projected transfer with a plasma welding current of $180 \mathrm{~A}$.

4) Compared to the droplet transfer and voltage-current waveform curves of GMAW in plasma GMAW-P hybrid welding and plasma-GMAW-P hybrid welding with a magnetic field, the droplet transfer period was changed slightly with the external magnetic field. However, the form and detaching position of the droplet transfer was transformed. When the GMAW current wasn't more than 140 A, droplet transfer was mainly repelled transfer under the external magnetic field. The detaching position was on the right side of the wire when the magnetic field current wasn't more than $3 \mathrm{~A}$. The detaching position of the droplet was located on the left side or in the direction of the wire when the magnetic field current exceeded $3 \mathrm{~A}$. When the GMAW current exceeded $140 \mathrm{~A}$ and the magnetic field current was less than 5 A, droplet transfer was spray transfer under the external magnetic field. Droplet transfer was transformed into projected transfer with a magnetic field current of $5 \mathrm{~A}$.

\section{Acknowledgments}

The research was financially supported by Shandong Provincial Natural Science Foundation (ZR2018MEE027), Shandong key research and development plan (2017GGX30132), Young Taishan Scholars Program of Shandong Province (tsqn20161062), Shandong Key research and development plan (2018GGX103032), State Oceanic Administration Marine Economic Innovation and Development Demonstration City Project (60M Underwater Marine and Ship Rapid Repair technology and equipment $\mathrm{R} \& \mathrm{D}$ and industrial chain construction projects), and Yantai Key R\&D Program (2019ZDCX006).

\section{References}

1. Hong, H., Han, Y., Du, M., and Tong, J. 2016. Investigation on droplet momentum in VPPA-GMAW hybrid welding of aluminum alloys. International Journal of Advanced Manufacturing Technology 86(5-8): 2301-2308. DOI: 10.1007/s00170-016-8381-2

2. Zhang, C., Ma. G., Nie, J., and Ye, J. 2015. Numerical simulation of AZ31B magnesium alloy in DE-GMAW welding process. International Journal of Advanced Manufacturing Technology 78(5-8): 1259-1264. DOI: 10.1007/s00170-014-6703-9

3. Chen, S. J., Wang, L. W., Xiao, J., and Wei, P. S. 2018. Arc 
behavior and droplet dynamics of AC GTAW-GMAW hybrid indirect arc. Welding Journal 97(3): 91-s to 98-s. DOI: 10.29391/ 2018.97.008

4. Huang, J., He, X., Guo, Y., Zhang, Z., Shi, Y., and Fan, D. 2017. Joining of aluminum alloys to galvanized mild steel by the pulsed DE-GMAW with the alternation of droplet transfer. Journal of Manufacturing Processes 25: 16-25. DOI: 10.1016/j.jmapro.2016. 10.003

5. Tusek, J., and Suban, M. 2013. Hybrid welding with arc and laser beam. Science \& Technology of Welding \& Joining 4(5): 308-311. DOI: 10.1179/136217199101537923

6. Liu, S., Zhang, F., Dong, S., Zhang, H., and Liu, F. 2018. Characteristics analysis of droplet transfer in laser-MAG hybrid welding process. International Journal of Heat and Mass Transfer 121: 805-811. DOI: 10.1016/j.ijheatmasstransfer.2018.01.047

7. Lou, X., Chen, M. A., Wu, C. S., and Ye, K. 2014. Humping and undercutting suppression mechanism for high speed TIG-MIG hybrid welding. Transactions of the China Welding Institution 35(8): 87-90.

8. Kanemaru, S., Sasaki, T., Sato, T., Mishima, H., Tashiro, S., and Tanaka, M. 2014. Study for TIG-MIG hybrid welding process. Welding in the World 58(1): 11-18. DOI: 10.1007/s40194-0130090-y

9. Yang, T., Xiong, J., and Chen, H. 2016. Effect of process parameters on tensile strength in plasma-MIG hybrid welding for 2219 aluminum alloy. International Journal of Advanced Manufacturing Technology 84(9-12): 2413-2421. DOI: 10.1007/s00170-0157901-9

10. Ton, H. 1975. Physical properties of the plasma-MIG welding arc. Journal of Physics D Applied Physics 8(8): 922-933. DOI: 10.1088/0022-3727/8/8/006

11. Bai, Y., Gao, H.-M., and Qiu, L. 2010. Droplet transition for plasma-MIG welding on aluminium alloys. Transactions of Nonferrous Metals Society of China 20(12): 2234-2239. DOI: doi.org/10.1016/S1003-6326(10)60634-6

12. Bai, Y., Gao, H.-M., Wu, L., Ma, Z.-H., and Cao, N. 2010. Influence of plasma-MIG welding parameters on aluminum weld porosity by orthogonal test. Transactions of Nonferrous Metals Society of China 20(8): 1392-1396. DOI: 10.1016/S10036326(09)60310-1

13. Cai, D., Han, S., Zheng, S., Luo, Z., Zhang, Y., and Wang, K. 2018. Microstructure and corrosion resistance of Al5083 alloy hybrid plasma-MIG welds. Journal of Materials Processing Technology 255: 530-535. DOI: 10.1016/j.jmatprotec.2017.12.033

14. Lee, H.-K., Park, S.-H., and Kang, C.-Y. 2015. Effect of plasma current on surface defects of plasma-MIG welding in cryogenic aluminum alloys. Journal of Materials Processing Technology 223: 203-215. DOI: 10.1016/j.jmatprotec.2015.04.008
15. Lee, H.-K., Chun, K.-S., Park, S.-H, and Kang, C.-Y. 2015. Control of surface defects on plasma-MIG hybrid welds in cryogenic aluminum alloys. International Journal of Naval Architecture and Ocean Engineering 7(4): 770-783. DOI: 10.1515/ijnaoe-20150054

16. Yurtisik, K., Tirkes, S., Dykhno, I., Gur, C. H., and Gurbuz, R. 2013. Characterization of duplex stainless steel weld metals obtained by hybrid plasma-gas metal arc welding. Soldagem \& Inspeção 18(3): 207-216. DOI: 10.1590/S0104-92242013000300003

17. Luo, Y., Zhu, Y., Xie, X., and Wan, R. 2016. Study on the transient impact energy of metal droplet transfer in P-MIG welding based on acoustic emission signals analysis. Materials \& Design 90: 22-28. DOI: 10.1016/j.matdes.2015.10.112

18. Lean, P. P., Gil, L., and Ureña, A. 2003. Dissimilar welds between unreinforced AA6082 and AA6092/SiC/25p composite by pulsed-MIG arc welding using unreinforced filler alloys (Al-5Mg and Al-5Si). Journal of Materials Processing Technology 143-144(1): 846-850. DOI: 10.1016/S0924-0136(03)00331-5

19. Mezrag, B., Beaume, F. D., Rouquette, S., and Benachour, M. 2018. Indirect approaches for estimating the efficiency of the cold metal transfer welding process. Science \& Technology of Welding \& Joining 23(6): 508-519. DOI: 10.1080/13621718.2017.1417806

20. Wu, K., Liang, Z., Yin, T., He, Z., and Zeng, M. 2018. Double pulse low-frequency modulation for high-power double-wire pulsed GMAW. Journal of Manufacturing Science and Engineering 140(9): 091004. DOI: 10.1115/1.4040319

21. Hertel, M., Rose, S., and Füssel, U. 2016. Numerical simulation of arc and droplet transfer in pulsed GMAW of mild steel in argon. Welding in the World 60(5): 1-7. DOI: 10.1007/s40194-0160362-4

22. Zhang, X., Zhao, Z., Wang, C., Yan, F., and Hu, X. 2016. The effect of external longitudinal magnetic field on laser-MIG hybrid welding. The International Journal of Advanced Manufacturing Technology 85(5-8): 1735-1743. DOI: 10.1007/s00170-015-8035-9

JIANG YU, BO WANG, HONGTAO ZHANG (zhanght@hitwh.edu.cn), PENG HE, and JICAI FENG are with State Key Laboratory of Advanced Welding and Joining, Harbin Institute of Technology, Harbin, China. YU, B. WANG, ZHANG, PENG CHEN, and FENG are with Shandong Provincial Key Laboratory of Special Welding Technology, Harbin Institute of Technology at Weihai, Weihai, China. B. WANG and ZHANG are also with Institute for Shipwelding Technology, Shandong Institute of Shipbuilding Technology, Weihai, China. QICHEN WANG and LIQIN WEI are with Yantai CIMC Raffles Offshore Ltd., Yantai, China. 